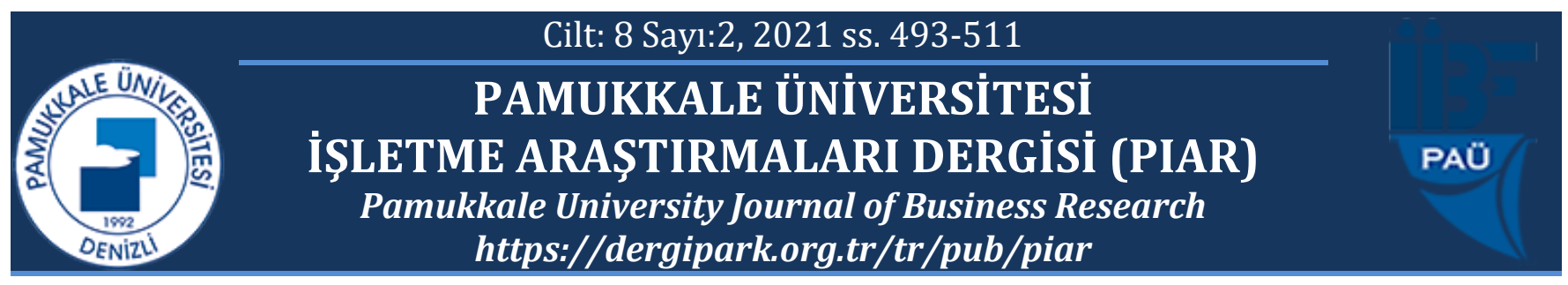

\title{
E7 Ülkelerinde Finansal Yenilik ve Ekonomik Büyüme İlişkisi: Bir Panel Nedensellik Analizi
}

\section{The Association between Financial Innovation and Economic Growth in E7 Countries: A Panel Causality Analysis}

\section{Ayşe ERGİN ÜNAL ${ }^{1 *}$}

\section{Serkan ŞAHİN ${ }^{2}$}

\footnotetext{
1 Tarsus Üniversitesi, Uygulamalı Bilimler Fakültesi, Finans ve Bankacılık Bölümü, ayseerginunal@tarsus.edu.tr, https://orcid.org/0000-0001-6551-8933

2 Tarsus Üniversitesi, Uygulamalı Bilimler Fakültesi, Finans ve Bankacılık Bölümü, serkansahin@tarsus.edu.tr, https://orcid.org/0000-0002-1927-1092

* Yazışılan Yazar/Corresponding author
}

\section{Öz}

Finansal sistemin gelişimini etkileyen unsurların başında gelen finansal yenilikler, yatırımların verimliliklerini, tasarrufları ve rekabet avantajın artırarak ekonomik gelişmişliğin artırılmasına katkı sağlamaktadır. Dolayısı ile ekonomik büyüme politikalarının geliştirilmesinde finansal yeniliklerin olası etkilerinin de dikkate alınması uygulanan politikaların etkinliğini artırabilmektedir. Dĭger yandan, ekonomik büyüme de finansal sistemin etkinliğini artırarak finansal yeniliklerin ortaya çıkışını teşvik edebilmektedir. Bu kapsamda, finansal yenilik ile ekonomik büyüme arasındaki ilişkinin belirlenmesi, ekonomik büyümeyi artıran faktörlerin ortaya konulabilmesi ve ekonomik rekabet gücünü artırıcı politikaları desteklenebilmesi açısından önem taşımaktadır. Bu çalışmanın amacı E7 ülkelerinde finansal yenilik ve ekonomik büyüme arasındaki ilişkinin panel nedensellik analizleri kullanularak incelenmesidir. Elde edilen bulgular farkl göstergeler dikkate alındı̆̆ında Çin ve Türkiye'de finansal yeniliklerin ekonomik büyümenin nedeni olduğunu, Rusya, Meksika ve Endonezya'da ise ekonomik büyümenin finansal yeniliklerin nedeni olduğunu göstermiştir. Bir başka ifade ile Çin ve Türkiye'de finansal yeniliklerin teşvik edilmesi ve finansal yeniliklerin nicelik ve nitelik olarak geliştirilmesi yolu ile ekonomik büyümenin artırılması mümkün gözükmektedir. Rusya, Meksika ve Endonezya'da ise ekonomik büyümenin finansal yeniliklerin ortaya çımasında teşvik edici bir unsur olduğu söylenebilir.

Anahtar kelimeler: Finansal yenilik, Panel Nedensellik Analizleri, Ekonomik büyüme, E7 Ülkeleri.

JEL kodlarn: O16, O47, G10

\begin{abstract}
Financial innovations, as one of the factors affecting the development of the financial system, contribute to the enhancement of economic development by increasing the efficiency of investments, savings and competitive advantage. Therefore, taking into account the effects of financial innovations on economic growth may increase policy effectiveness. On the other hand, economic growth may also boost the rise of financial innovations by improving the efficiency of the financial system. In this context, it is vital to determine the association between financial innovation and economic growth in terms of determining the factors that increase economic growth and supporting policies that increase economic competitiveness. The purpose of this paper is to investigate the interaction between financial innovation and economic growth in E7 countries using panel causality analysis. Findings revealed that financial innovation causes economic growth in China and Turkey whereas, economic growth causes financial innovation in Russia, Mexico and Indonesia when different indicators are taken into consideration. In other words, it is possible to boost economic growth by encouraging financial innovations in quantity and quality. In Russia, Mexico and Indonesia, on the other hand, economic growth is an encouraging factor for the rise of financial innovations.
\end{abstract}

Keywords: Financial Innovation, Economic Growth, Panel Causality Analysis, E7 Countries.

JEL codes: O16, O47, G10 


\section{GİRIŞ̧}

Finansal ve ekonomik göstergelerdeki birlikte değişim, sermaye hareketlerindeki serbestleşme bunun yanı sıra ülke ekonomilerinde finansal kriz dönemlerinde gözlemlenen daralmalar büyüme ve finansal göstergeler arasında bir bağlantı olduğu düşüncesini oluşturmaktadır. Keza, Levine (2005: 921-923) finansal gelişmişlik ve ekonomik performans arasındaki ilişkisinin varlığından bahsederek finansal sistemin ekonomik performansın önemli bir unsuru olduğunu ifade etmiştir. Finansal gelişmişlik ve ekonomik performans ilişkisinin unsurlarından birisi olan finansal aracı hizmetlerinden başlamak üzere, yenilik ve büyümedeki rolü Schumpeter (1934) tarafından geniş bir biçimde ele alınmış, teorinin gelişmekte olan ve gelişmiş ülke ekonomileri üzerindeki çıkarımları araştırmalara (Laumas, 1962; Thanawala, 1994; Bazhal, 2016) konu olmuştur.

Finansal yenilik kavramının tanımlanması üzerinde fikir birliğine varılmadığı dikkat çekmektedir. Tufano (2002: 4) ekonominin vaz geçilmez bir unsuru olarak değerlendirdiği finansal yenilikleri finansal teknolojilerin yanı sıra yeni finansal araçlar, yeni finansal kurumlar veya piyasalar ortaya çıkarma süreci olarak tanımlamıştır. Frame ve White (2014: 4) finansal yenilikleri, riskleri ve maliyetleri azaltan, daha gelişmiş bir finansal varlık veya hizmet sunarak finansal müşterilerin gereksinimlerini karşılayan unsurlar olarak tanımlamıştır. Bank for International Settlement-BIS (1986: 169-185) finansal yenilikleri talep ve arz yönlü olarak iki farklı kategoride değerlendirmiş ve risk transferi ile ilgili yenilikler, likidite sağlayıcı yenilikler, kredi genişlemesi sağlayan yenilikler, özsermaye sağlayan yenlikler olmak üzere dört ana başlık altında sınıflandırmıştır. Shiller (2004: 3) ise finansal yenilikleri radikal bir değişim olarak değerlendirmiştir. Farklı tanımlamalardan anlaşıldığ üzere üzerinde fikir birliğine varılmış kavramsal finansal yenilik tanımının var olmadığı görülmektedir. Tanımlamadaki farklılıklar finansal yeniliklerin nasıl ortaya çıtı̆̆ı ve geliştiği konusunda da farklı görüşlerin ortaya çıkmasına neden olmuştur.

Finansal yenilikleri ortaya çıaran faktörler arasında yasal düzenlemeler (Silber, 1983: 89; Miller, 1986: 460-470; Kaplan, 1999: 2-10; Cömert ve Ebstein, 2016: 2), finansal sistemdeki kisıtlar (Cömert ve Ebstein, 2016: 2), ekonomik ve teknolojik gelişmeler (Miller, 1986: 460470) ile enflasyon ve faiz dalgalanmaları (Kaplan, 1999: 2-10) yer almaktadır. Ortaya çıkış şekilleri üzerinde bir fikir birliği olmasa da finansal yeniliklerin etkilerinin incelendiği alanların başında ekonomik büyüme gelmektedir. Finansal yeniliklerin ekonomik büyüme ile yakından ilişkili olduğu (Kaplan (1999: 2-10), finansal yeniliklerin teknolojik gelişmenin yanı sıra ekonomik büyüme düzeyinin belirlenmesinde baskın bir role sahip olduğu (Laeven vd., 2015: 22) ve hatta ekonomiye olan katkısının da ötesine geçilerek finansal yeniliklerin, toplumsal gelişimin vaz geçilmez bir parçası olduğu (Shiller, 2013: 21-22) ifade edilmektedir. Finansal yeniliklerin hangi araçlar yolu ile ekonomik büyümeyi desteklediği yönünde farklı yaklaşımlar bulunmaktadır.

Bir bakış açısında göre, finansal yenilikler üç farklı yolla ekonomik performansı iyileştirebilmektedir. Buna göre, finansal piyasalarda risk paylaşımı, riskten korunma ve risk transferi vb. fayda sağlayan finansal araçlar ile piyasanın etkinlik düzeyine katkı sağlayarak, işlem maliyetlerini azaltıp likiditeyi artırarak ve son olarak temsilci maliyetlerini azaltarak ekonomik performans artırılabilmektedir (Merton, 1992: 17). Bunun yanı sıra, finansal yenilikler risk dağıtım alternatiflerini çeşitlendirerek, asimetrik bilgi ve temsil maliyetlerini 
azaltarak, finansal sistemin etkinliğini artırabilmekte bu yolla da ekonomik büyümeye katk1 sağlayabilmektedir (Merton, 1995: 462-463).

Yeni finansal araçlar, hizmetler, kurumlar, teknolojiler ve piyasalar biçiminde ortaya çıkan finansal yenilikler, fon fazlasını en verimli şekilde yatırımlara yönlendirerek sermaye birikimi dolayısıyla ekonomik büyümeyi artırabilmektedir (Mishra, 2009: 59-62). Finansal yenilikler kaynak dağılımının etkinliğini artırarak, büyümedeki oynaklığı azaltabilmekte, finansal aracılık maliyetlerini düşürerek, risk yönetim alternatiflerini artırmakta ve riskin taraflar arasında transferini mümkün kılabilmektedir (Mishra, 2009: 59-62). Finansal yenilikler finansal varlıkların çeşitliliğini artırarak piyasaların likiditesini artırabilmekte bu yolla da sermaye maliyetini düşürerek finansal sistemin etkinliğini sağlayabilmektedir (Jenkinson vd., 2008: 5-8). Finansal varlıkların çeşitliliğini artması ise sermaye birikimini çoğaltarak ekonomik büyümeyi artırabilmektedir (Chou, 2007: 78).

Genel olarak değerlendirildiğinde finansal gelişmenin katalizörü tanımlayabileceğimiz finansal yeniliklerin ekonomik büyümenin bir öncü göstergesi olarak ele alınabildiği söylenebilir. Bu noktadan hareketle finansal yenilik ve ekonomik büyüme arasındaki ilişkinin incelenmesi özellikle finansal sistemin gelişimine yönelik politika geliştirenler ve finansal piyasaların düzenleyicileri açısından önem arz ettiği düşünülmektedir. Ancak, finansal yenilik kavramına yönelik tanım farklılıkları, finansal yenilik kavramının temsilcisi olan göstergelerin belirlenmesindeki zorluklar ve veriye ulaşmada yaşanan kısıtlar konu üzerine yürütülen çalışmaların sınırlı kalmasına neden olmuştur. Bu çalışmada finansal yenilikler ile temel makroekonomik göstergelerden biri olan ekonomik büyüme arasındaki ilişkinin teorik ve uygulamalı olarak E7 ülkeleri için incelenmesi amaçlanmış ve bu yolla literatüre katkı sunulması hedeflenmiştir. Çalışmanın bundan sonraki ikinci bölümünde finansal yenilik ve ekonomik büyüme ilişkisini inceleyen araştırmalara yer verilmiş, üçüncü bölümde veri ve araştırma modeli açıklanmış, dördüncü bölümde bulgular sunulmuş ve beşinci bölümde sonuç ve değerlendirilmeler aktarılmıştır.

\section{LITERATÜR}

Geçmiş çalışmalar incelendiğinde finansal yenilik ve ekonomik büyüme arasındaki ilişkinin araştırıldığ çalışmaların sayıca azlığı dikkat çekmekte olup yürütülen çalışmaların finansal yenilik-ekonomik büyüme ilişkisinden ziyade daha çok finansal gelişme ve ekonomik büyüme ilişkisini (Jung, 1986; Gregorio ve Guidotti, 1995; Demetriades ve Hussein, 1996; Arestis ve Demitrades, 1997; Allen ve Ndikumana; 1998; Ram, 1999; Khan ve Senhadji, 2000; Hermes ve Lensink, 2003; Calderón ve Liu, 2003; Aslan, ve Küçükaksoy, 2006; Kandır vd., 2007; Öztürk, 2008; Acaravc1 vd., 2009; Hassan vd., 2011; Zhang vd., 2012; Öztürk ve Acaravc1, 2013; Rafindadi, 2016; Pradhan vd. 2016; Sbia vd., 2017; Rafindadi ve Öztürk, 2017; Durusu-Ciftci vd., 2017; Škare vd., 2018; Fetai, 2018; Asteriou ve Spanos, 2019; Eyüboğlu ve Akan, 2019; Wu vd., 2020; Abdouli ve Hammami, 2020; Soltani vd., 2021) konu aldığ1 görülmektedir. Finansal gelişme ve ekonomik büyüme etkileşimini irdeleyen araştırmalardan ulaşılan genel kanı finansal gelişmenin ekonomik büyüme üzerinde pozitif bir etkisi bulunduğu yönündedir.

Finansal yenilik ve ekonomik büyüme ilişkisini inceleyen çalışmaların nispeten sınırlı kalmakla birlikte bu çalışmalardan birinde Beck vd. (2016: 28) 32 ülke üzerinde 1996-2010 dönemi için yürüttükleri araştırma sonucunda finansal yeniliklerin ekonomik büyümeyi 
pozitif yönde etkilediği bu etkinin ise büyüme potansiyeli yüksek olan ülkelerde daha görülür olduğu sonucuna ulaşmışlardır. Hao ve Hunter (1997: 64-71) 63 ülke üzerine yürüttüğü çalışmada 1970-1988 döneminde finansal yenilik ve ekonomik büyüme etkileşimini incelemiştir. Araştırmacılar finansal yeniliklerin ekonomik büyümeyi pozitif yönde etkilediğini gösteren sonuçlara ulaşmışlardır. Bernier ve Plouffe (2019: 162-172) 23 ülke üzerine yürüttüğü çalışmada 1996-2014 döneminde finansal yeniliklerin brüt sermaye oluşumunu pozitif yönde etkilediğini yönünde bulgulara ulaşmışlar ancak finansal yeniliklerin ekonomik büyümeyi artırdığına yönelik herhangi bir bulguya ulaşamamışlardır.

Valverde vd. (2007: 311) finansal kurumlardan biri olan bankalardaki ürün odaklı finansal yeniliklerin ekonomik büyümeye olan etkisini İspanya kapsamında incelemiş ve analiz sonucunda ürün ve hizmet sunumundaki yeniliklerin bölgesel gayri safi yurtiçi hâsıla, yatırım ve brüt tasarruflar üzerinde pozitif etkiye sahip olduğunu belirlemişlerdir. Nazir vd. (2020: 6036) 1970-2016 döneminde Çin, Hindistan ve Pakistan'daki finansal yenilik ve ekonomik büyüme etkileşimini nedensellik analizleri kapsamında araştırmışlardır. ARDL ve Granger nedensellik tabanlı Hata Düzeltme modeli kullanılarak yürütülen analizlerde, finansal yeniliklerin ekonomik büyümeyi pozitif yönde etkilediği belirlenmiştir. Leaven vd. (2015) Schumpeterian modeli oluşturarak yaptıkları çalışmalarında finansal yeniliklerin teknolojik yeniliklerin ve ekonomik büyümenin itici gücü olduğunu, finansal yenilikler olmazsa ekonomik büyümenin devam edemeyeceği görüşünü ampirik bulgular ile desteklemiştir.

Qamruzzaman ve Wei (2018: 1) 1980-2016 dönemi için Bangledeş'de finansal yenilik, borsanın gelişimi ve ekonomik büyüme arasındaki dinamik ilişkiyi incelemiştir. Yürütülen ARDL ve nedensellik analizleri neticesinde finansal yenilikler ile ekonomik büyüme ilişkisinin iki yönlü olduğu belirlenmiştir. Buna göre, finansal sistemdeki yenilikler ekonomik büyümeyi tetiklemektedir. Okafor vd. (2017: 1) finansal teknolojilerdeki yeniliklerin ekonomik büyüme üzerindeki etkisini 2009-2014 döneminde Nijerya için incelemişlerdir. Elde edilen bulgular ATM, internet ve mobil ödeme gibi finansal teknolojilerin kullanımının ekonomik büyümeyi pozitif yönde etkilediğini göstermiştir.

Ansong (2011: 93-94) vd. 1963'ten 2006'ya kadar olan dönemde Gana'daki finansal yeniliklerin finansal tasarruflar üzerindeki etkilerini incelediği çalışmasında finansal yeniliklerin kısa vadede finansal tasarruflarda bir azalmaya yol açtığını tespit etmiştir. Bulunan sonucun tasarruf-yatırım kanalı ve dolayısıyla ekonomik büyümede değişim meydana getireceği düşünülmektedir. Bara vd. (2016: 491-493) Güney Afrika Kalkınma Topluluğu (SADC) üye ülkelerinde finansal yenilik ve ekonomik büyüme arasındaki ilişkiyi incelemişlerdir. ARDL yaklaşımının kullanıldığı analizler sonucunda söz konusu iki faktör arasında pozitif bir ilişki tespit edilmiştir. Panel Granger nedensellik testleri sonucunda ise finansal yenilik ile büyüme göstergelerinin herhangi bir nedensellik bağlantısı içermediği tespit edilmiştir.

Türkiye' de finansal yenilikler üzerine yapılan geçmiş çalışmalar incelendiğinde sayıca azlık dikkat çekmekte olup finansal yeniliklerden ziyade finansal gelişmişlik düzeyi ve ekonomik büyüme üzerine yapılan çalışmalar dikkat çekmektedir. Türkiye' de finansal yenilik üzerine yapılan çalışmalardan Kaplan (1999) finansal yenilikler ve piyasalar üzerine etkilerini incelerken Öncü vd. (2012; 2013), finansal yeniliklerin seçilmiş işletme performansına 
etkisini incelemişler, Büyükakın vd. (2011) finansal yenilik-tüketim harcamaları ilişkisini ampirik olarak test etmiş, Ayaydın vd. (2019) finansal yenilik ve ekonomik büyüme ilişkisini incelemiş ve Cömert ve Epstein (2016) finansal yenilik yazınındaki gelişmeleri, Yetiz ve Ergin Ünal (2018) Türkiye'de finansal yeniliklerin bankacılık sektörü üzerindeki etkilerini teorik olarak incelemişlerdir. Finansal yenilik ve ekonomik büyüme ilişkisini inceleyen çalışmalarda Türkiye'nin de içinde yer aldığı E7 ülkeleri üzerine yürütülen herhangi bir çalışmaya ise rastlanılmamıştır. Bu kapsamda çalışmanın literatüre katkı sağlayan özgün çalışma olduğu düşünülmektedir.

\section{VERİ SETI VE YÖNETIM}

Finansal yenilikler aracı kurumların belirli faaliyet konuları üzerinde uzmanlaşmasını ve belirli amaca yönelik ihtisaslaşmış piyasaların ortaya çıkmasını sağladığından, her biri benzersiz özelliklere sahip çeşitli finansal araçların gelişimine katkıda bulunmaktadır. Finansal ürünlerin artan çeşitliliği, tasarruf sahiplerinin ve/veya borçluların özel gereksinimlerine daha uygun araçlar arasında seçim yapabilmelerine imkân tanımakta ve bu yolla finansal varlıklara yönelik tasarrufların yanı sıra borç kullanımını da artırmaktadır (Bhatt, 1987: 45-46). Bu açıdan değerlendirildiğinde, finansal yeniliklerin kredi hacminde genişlemeye yol açması olası görülmektedir.

Finansal yeniliklerin kredi piyasasını ilgilendiren bir başka boyutu ise bilgi asimetrisi problemi ile ilişkilidir. Finansal piyasalarda var olan asimetrik bilgi problemi tüm finansal piyasaların işleyişini bozabildiği gibi kredi piyasasının da işlevselliğini olumsuz yönde etkileyebilmekledir. Asimetrik bilginin neden olduğu ters seçim problemi kredi veren kuruluşların kredi tahsis politikalarının istenenden daha katı olmasına yol açabilmekte, kredi veren kuruluşları yüksek teminatlar istemeye yöneltebilmekte ve sonuç olarak kredi talebi için gerekli şartları sağlayan müşteri potansiyelinin azalmasına ve kredi piyasasının daralmasina neden olabilmektedir.

Finansal yenilikler ise kredi piyasasında hem borç verenlerin hem de borç alanların risklerini azaltabilmektedir. Buna göre, kredilendirme konusundaki yenilikler, kredi ödeme gücü yüksek borçluların seçilmesi veya ters seçimle ilgili risklerin önlenmesinde çok ekonomik ve etkili bir araç olarak kullanılabilmektedir (Bhatt, 1987: 46-47). Bu bakış açısı ile finansal yenilikler kredi piyasasında sıklıkla karşılaşılan ters seçim problemini azaltarak kredi veren kuruluşların arzu etkileri risk düzeyindeki müşteriler ile eşleşmelerine imkân tanımaktadır. Finansal yenilikler sayesinde azalan ters seçim problemi ile kredi piyasasının daha etkin olması sağlanabilmekte, kredi piyasasındaki işlem maliyetleri azaltılabilmekte ve sonuç olarak kredi hacminde genişleme sağlanabilmektedir.

Bunun yanı sıra, son yıllarda bankacılık sektörünün büyüme alanlardan birisi olan dijital bankacılık kanalları ise bir finansal yenilik olarak kredi kullanımını etkileyebilmektedir. Günümüzde bankaların kredi kullanmak isteyen müşterilerine dijital kanallar yolu ile ulaşabildikleri, kredi tahsisinin şubeye gitmeden dijital kanallar aracılığı ile gerçekleşmesini sağlayabildikleri görülmektedir. Buna göre, daha kolay ulaşılabilir olması, zaman tasarrufu sağlaması, kişiye/kuruma özel teklifler/oranlar sunulabilmesi ve daha düşük işlem maliyetine sahip olması nedeniyle dijital bankacılık kanalları kredi kullanımını artırabilmesi olası görülmektedir. 
Diğer taraftan menkul kıymetleştirme ve kitlesel fonlama gibi finansal yenilikler ise firmaların kredi kullanımlarına alternatif bir araç olarak kredi hacminin daralmasına neden olabilmektedir. Keza, Günceler ve Kesebir (2018: 88) Türkiye'de finansal hizmet sağlayan işletmeler üzerine gerçekleştirdiği analizlerde menkul kıymetleştirmenin likidite sağlayarak firmaların finansman ihtiyacını azalttığını bu nedenle de banka kredilerine alternatif bir finansman aracı olarak kullanılabileceğini ifade etmiştir.

Genel olarak değerlendirildiğinde söz konusu mekanizmaların işleyişinin yasal düzenlemeler ile kamu ve özel sektör bankalarının kredi politikalarına göre ülkeler bazında farklılaşabildiği düşünülmektedir. Bu çalışmada incelenen Brezilya, Çin, Endonezya, Hindistan, Meksika, Rusya ve Türkiye'de farklı yasal düzenlemeler altında işleyen farklı bankacılık sektörü yapılanmaları bulunmaktadır. Bu nedenle bahsi geçen bu yedi ülkenin tamamında yukarıda ifade edilen mekanizmaların aynı yönde ve aynı etki ile hareket ettiğini söylemek mümkün olmayacaktır. Bir başka ifade ile bir ülkenin bankacıllk sektöründeki kredi tahsis politikası ve ilkeleri bir başka ülkenin bankacılık sektöründeki kredi tahsis politika ve ilkeleri ile uyumlu olmayabilmektedir. Söz konusu ülkelerdeki yasal düzenlemelere ilişkin farklılıklar ile bankacılık sektörünün finansal sistemdeki rolüne ilişkin farklılıklar, finansal yeniliklerin ülke bazındaki etkisinin farklılaşmasına neden olabilmektedir. Ülkeler arasındaki farklılıkların yanı sıra aynı ülke içinde de ticari bankaların faaliyet amaçlarına ve kamu ve özel sermayeli bankacılık yapısına göre farklılıklar gelişebilmektedir. Bir başka ifade ile çalışmada incelenen ülkeler bazında herhangi bir ülkedeki kredi tahsis politikası ilgili ülkede faaliyet gösteren ticari bankalar arasında dahi farklılık gösterebilmektedir. Bu nedenle tüm ülkeler bazında ortak bir finansal yenilik göstergesi oluşturmak oldukça zordur. Ekonomik büyüme ile ilgili göstergelerin ne olmasi gerektiğine yönelik fikir birliğine varıldığı gözlemlenmekle birlikte Nazir vd. (2020)'nin de ifade etiği üzere finansal yeniliklerin göstergesi olarak üzerinde fikir birliğine varılmış tek bir gösterge bulunmamaktadır. Dolaysısı ile literatürde farklı bakış açıları ile farklı göstergelerin finansal yeniliklerin temsilcisi olarak ele alınabildiği görülmektedir.

$\mathrm{Bu}$ çalışmada finansal yenilik ve ekonomik büyüme arasındaki bağlantı Brezilya, Çin, Endonezya, Hindistan, Meksika, Rusya ve Türkiye'den oluşan E7 ülkeleri için 2002-2019 dönemindeki yıllık veriler baz alınarak incelenmiştir. Geçmiş çalışmalar incelendiğinde finansal yeniliklerin göstergesi olarak ATM, kredi kartı sayısı, kredi hacmi, toplam kredilerin toplam varlıklara oranı, takipteki krediler rasyosu (Gündoğdu ve Taşkın, 2017), bankacılık sektöründe varlık karlılığı, bankacılık sektörü yoğunlaşma endeksi, dar kapsamlı (M1) ve geniş kapsamlı (M3) para arzı (Ajide, 2016), ATM, internet bankacılığı, POS makinesi ve mobil bankacılık araçlı̆̆ ile gerçekleştirilen işlemler (Tahir et al., 2018) ile özel sektöre kullandırılan krediler (Idun ve Aboagye, 2014; Laeven vd., 2015; Bara ve Mudxingiri, 2016; Bara vd., 2016; Nazir vd., 2020) ve geniş kapsamlı para arz1 (M2) / dar kapsamlı para arz1 (M1) (Arrau vd., 1995, Ansong vd., 2011; Bara ve Mudxingiri, 2016; Bara vd., 2016; Nazir vd., 2020; Khan vd., 2021) göstergelerinin temsilci olarak kullanıldığ1 dikkat çekmektedir. Buna göre, finansal yeniliklerin özel sektöre kullandırılan krediler ve geniş kapsamlı para arzı (M2) / dar kapsamlı para arzı (M1) ile sıklıkla temsil edildiği görülmektedir. Özel sektöre kullandırılan kredilerdeki artış hızının finansal yenilikleri teşvik etmesi (Amore, 2013: 837) ve geçmiş çalışmalarda (Idun ve Aboagye, 2014; Laeven vd., 2015; Bara ve Mudxingiri, 2016; Bara vd., 2016; Nazir vd., 2020) sıklıkla kullanılması nedeniyle finansal yeniliklerin birinci 
temsilcisi olarak özel sektöre kullandırılan kredilerdeki büyüme oranı (BÖSK) tercih edilmiştir.

Bunun yanı sıra, daha geniş ölçekli bir dizi para ikamesinin dar paraya kıyasla geniş para tanımina daha fazla yansitıliyor olması (Ansong vd., 2011: 103) ve yukarıda bahsedilen argümanlar ve geçmiş çalışmalarda (Arrau vd., 1995, Ansong vd., 2011; Bara ve Mudxingiri, 2016; Bara vd., 2016; Nazir vd., 2020; Khan vd., 2021) sıklıkla kullanılması nedeniyle M2/M1 oranı finansal yeniliğin ikincil temsilcisi olarak analizlere dâhil edilmiştir. Ekonomik büyümenin temel göstergesi olarak Gayri Safi Yurt İçi Hâsıla Büyüme Oranı (BGSYH) esas alınmakla birlikte ekonomik büyümenin alternatif bir göstergesi olarak Bertay vd. (2017) tarafından kullanılan Brüt Sermaye Oluşumu büyüme oranına (BBSO) da çalışma kapsamında yer verilmiştir.

Çalışma kapsamında analiz edilen değişkenler ve kurgulanan modeller Tablo 1'de sunulmuştur. Tablo 1'de yer aldığı üzere ele alınan finansal yenilik göstergeleri ayrı birer model kapsamında incelenmiştir. Söz konusu iki finansal yenilik göstergesinin ekonomik büyümeyi etkileyen ayrı birer faktör olmaması, bir başka ifade ile her iki göstergenin de aynı faktörün (finansal yenilik) bir temsilcisi olarak ele alınmış olması, çok değişkenli bazı denklem tahminlerinde olduğunun aksine söz konusu faktörlerin kombinasyonun anlamlı olmaması, aynı faktörün birbiri ile ilintili göstergelerinin aynı denklemde yer almasının çoklu doğrusal bağlantı sorununu beraberinde getirebiliyor olması ve son olarak Sweet ve Grace-Martin (2012: 161-162)'in ifade ettiği üzere tüm değişkenlerin aynı modelde incelenmesinin var olan mevcut ilişkilerin beklenmedik bir şekilde ortadan kaybolmasına yol açabilmesi nedeniyle finansal yenilik göstergeleri ile ekonomik büyüme arasındaki ilişki farklı modeller kapsamında ele alınmıştır.

Tablo 1. Çalışmada Kullanılan Değişkenler ve Kurgulanan Modeller

\begin{tabular}{|l|l|l|}
\hline $\begin{array}{c}\text { Araştırma } \\
\text { Modelleri }\end{array}$ & \multicolumn{1}{|c|}{ Kullanılan Değişkenler } & \multicolumn{1}{|c|}{ Kısaltmalar } \\
\hline \multirow{2}{*}{ Model I } & Brüt Sermaye Oluşumu Büyüme Oranı & BBSO \\
\cline { 2 - 3 } & Özel Sektöre Kullandırılan Kredilerdeki Büyüme Oranı & BÖSK \\
\hline \multirow{2}{*}{ Model II } & Gayri Safi Yurt İçi Hâsıla Büyüme Oranı & BGSYH \\
\cline { 2 - 3 } & Özel Sektöre Kullandırılan Kredilerdeki Büyüme Oranı & BÖSK \\
\hline \multirow{2}{*}{ Model III } & Brüt Sermaye Oluşumu Büyüme Oranı & BBSO \\
\cline { 2 - 3 } & Geniş Kapsamlı Para Arzı/Dar Kapsamlı Para Arzı & M2/M1 \\
\hline \multirow{2}{*}{ Model IV } & Gayri Safi Yurt İçi Hâsıla Büyüme Oranı & BGSYH \\
\cline { 2 - 3 } & Geniş Kapsamlı Para Arzı/Dar Kapsamlı Para Arzı & M2/M1 \\
\hline
\end{tabular}

Gayri Safi Yurt İçi Hâsıla büyüme oranı, Geniş Kapsamlı Para Arzı (M2) ve özel sektöre kullandırılan kredilere ilişkin veriler Dünya Bankası veri tabanından (World Development Indicators, 2020) alınmış, Dar kapsamlı Para Arzı (M1) verisi ise ABD St. Lois Merkez Bankası veri tabanından (FRED-Federal Reserve Economic Data) elde edilmiştir. FRED veri tabanında Meksika'nın 2019 yılına ait M1 verisi eksik olduğundan bu veri Meksika merkez bankasından (Banxico, 2020) elde edilerek tamamlanmıştır. Çalışmada kullanılan M2/M1 değişkeni ilgili veri tabanlarından elde edilen veriler doğrultusunda yazarlar tarafından M2 verisinin M1 verisine oranlanması yolu ile hesaplanmıştır. 
Değişkenlerin belirlenmesinin ardından panel veri yöntemine geçilmiştir. Bu aşamada ilk olarak yatay kesit birimleri arasındaki kesit bağımlılı̆̆ incelenmiştir. Bu amaçla Breusch and Pagan (1980) tarafından geliştirilen LM testi, Peseran (2004) CD testi, Peseran (2004) tarafından geliştirilen düzeltilmiş LM istatistiği ve Baltagi vd. (2012) tarafından geliştirilen Bias-corrected scaled LM testi uygulanmış elde edilen bulgulara Tablo 2' de yer verilmiştir.

Tablo 2. Yatay Kesit Bağımlılı̆̆1 Testleri

\begin{tabular}{|l|c|c|c|c|}
\hline & BBSO & BGSYH & BÖSK & M2/M1 \\
\hline LM (Breusch ve Pagan, 1980) & $48.43871^{* * *}$ & $72.21328^{* * *}$ & $35.74970^{* * *}$ & $190.2034^{* * *}$ \\
\hline Peseran scaled LM (Pesaran, 2004) & $4.233886^{* * *}$ & $7.902380^{* * *}$ & $2.275929^{* * *}$ & $26.10865^{* * *}$ \\
\hline $\begin{array}{l}\text { Bias-corrected scaled LM (Baltagi vd., } \\
\text { 2012) }\end{array}$ & $4.028003^{* * *}$ & $7.696498^{* * *}$ & $2.070046^{* * *}$ & $25.90277^{* * *}$ \\
\hline Pesaran CD (Pesaran, 2004) & $4.606958^{* * *}$ & $6.566012^{* * * *}$ & 1.059199 & -0.327383 \\
\hline
\end{tabular}

Not: *, ** ve ${ }^{* * *}$ "H $\mathrm{H}_{0}=$ Yatay Kesit Bağımlılı̆̆ Yoktur" boş hipotezin sırasıla \%90, \%95 ve \%99 önem düzeyinde reddedildiğini ifade etmektedir.

Tablo 2 incelendiğinde uygulanan tüm testler BBSO, BGSYH değişkenleri için yatay kesit bağımlılığının var olduğunu ortaya koymuştur. BÖSK, M2/M1 değişkenleri için yürütülen dört farklı yatay kesit bağımlılığı testinin üçünde yatay kesit bağımlılığının var olduğu belirlenmiştir. $\mathrm{Bu}$ nedenle söz konusu faktörler arasındaki nedensellik ilişkisinin incelenmesinde yatay kesit bağımlılığını dikkate alan yaklaşımların tercih edilmesi gerektiği görülmektedir. Bu kapsamda, çalışmada söz konusu faktörler arasındaki nedensellik ilişkisi yatay kesit bağımlılığının dikkate alındığı Kónya (2006) yaklaşımı ile incelenmiştir. Kónya (2006) tarafından geliştirilen ve Bootstrap kritik değerlerinin hesaplanmasına dayalı olarak yürütülen nedensellik analizleri Denklem-1 ve Denklem-2'deki ifade edilebilmektedir (Kónya, 2006);

$$
\begin{gathered}
Y_{1, t}=\alpha_{1,1}+\sum_{i=1}^{p y_{1}} \varphi_{1,1, k} Y_{1, t-i}+\sum_{i=1}^{p x_{1}} \delta_{1,1, i} X_{1, t-i}+\varepsilon_{1,1, t} \\
Y_{2, t}=\alpha_{1,2}+\sum_{i=1}^{p y_{1}} \varphi_{1,2, k} Y_{2, t-i}+\sum_{i=1}^{p x_{1}} \delta_{1,2, i} X_{2, t-i}+\varepsilon_{1,2, t} \\
\vdots \\
\vdots \\
Y_{N, t}=\alpha_{1, N}+\sum_{i=1}^{p y_{1}} \varphi_{1, N, i} Y_{N, t-i}+\sum_{i=1}^{p x_{1}} \delta_{1, N, i} X_{N, t-i}+\varepsilon_{1, N, t}
\end{gathered}
$$




$$
\begin{gathered}
X_{1, t}=\alpha_{2,1}+\sum_{i=1}^{p y_{2}} \varphi_{2,1, i} Y_{1, t-i}+\sum_{i=1}^{p x_{2}} \delta_{2,1, i} X_{1, t-i}+\varepsilon_{2,1, t} \\
X_{2, t}=\alpha_{2,2}+\sum_{i=1}^{p y_{2}} \varphi_{2,2, k} Y_{2, t-i}+\sum_{k=1}^{p x_{2}} \delta_{2,2, i} X_{2, t-i}+\varepsilon_{2,2, t} \\
\vdots \\
\vdots \\
X_{N, t}=\alpha_{2, N}+\sum_{i=1}^{p y_{2}} \varphi_{2, N, i} Y_{N, t-i}+\sum_{i=1}^{p x_{2}} \delta_{2, N, i} X_{N, t-i}+\varepsilon_{2, N, t}
\end{gathered}
$$

$\mathrm{Bu}$ yaklaşımın en önemli avantajları arasında zaman serilerine ilişkin durağanlık gibi temel varsayımları olmadan uygulanabiliyor olması gelmektedir. Bir diğer önemli avantajının ise seriler arasında eşbütünleşme ilişkisinin incelenmesine gerek olmadan nedensellik analizlerinin yürütülebiliyor olmasıdır (Kónya, 2006: 991). Çalışmamızda verilere ilişkin yatay kesit bağımlılığının bulunması nedeniyle bu yaklaşım benimsenmiştir. Bu yaklaşımın bir diğer avantajı da yatay kesit birimleri bazında nedensellik analizlerinin yürütülebiliyor olmasıdır. Bu yaklaşımın kullanması ile çalışmamız kapsamında her bir ülke için sonuçlar elde edilerek karşılaştırma olanağı elde edilebilmektedir. Veri kaynaklarının ve yöntemin açıklanmasının ardından Kónya (2006) bootstrap nedensellik analizleri sonucunda elde edilen bulgular çalışmanın bundan sonraki bulgular bölümünde sunulmuştur.

\section{BULGULAR}

E7 ülkeleri arasında yatay kesit bağımlılı̆̆ının varlığına ilişkin bulguların sunulmasından ardından yatay kesit bağımlılı̆̆ını dikkate alan Bootstrap panel nedensellik analizlerine geçilmiştir. Bu kapsamda ilk olarak Model I'de kurgulanan Brüt Sermaye Oluşumu Büyüme Oranı (BBSO) ile Özel Sektöre Kullandırılan Kredilerdeki Büyüme Oranı (BÖSK) arasındaki ilişki incelenmiş ve ulaşılan bulgular Tablo 3'de sunulmuştur.

Tablo 3. Panel Nedensellik Analizi Sonuçları (Model I)

\begin{tabular}{|l|l|l|l|l|l|l|l|l|}
\hline & \multicolumn{2}{|l}{ BBSO $\rightarrow$ BÖSK } & \multicolumn{2}{l}{ BÖSK $\rightarrow$ BBSO } \\
\hline Ülkeler & İstatistik & \multicolumn{2}{l}{ Bootstrap Kritik Değerler } & İstatistik & \multicolumn{2}{l|}{$\begin{array}{l}\text { Bootstrap } \\
\text { Değerler }\end{array}$} \\
\hline & & $1 \%$ & $5 \%$ & $10 \%$ & & $1 \%$ & $5 \%$ & $10 \%$ \\
\hline Brezilya & 0.029 & 37.205 & 17.045 & 10.844 & 0.311 & 27.059 & 12.614 & 8.534 \\
\hline Çin & 2.916 & 20.545 & 10.361 & 6.485 & 0.195 & 18.279 & 9.605 & 6.060 \\
\hline Endonezya & $6.761^{*}$ & 19.339 & 8.532 & 5.721 & 6.590 & 30.838 & 17.795 & 11.616 \\
\hline Hindistan & 0.075 & 31.713 & 15.440 & 9.536 & 0.005 & 54.084 & 24.555 & 16.086 \\
\hline Meksika & 2.642 & 21.364 & 9.652 & 6.766 & 0.034 & 42.304 & 21.842 & 15.093 \\
\hline
\end{tabular}




\begin{tabular}{|l|l|l|l|l|l|l|l|l|}
\hline Rusya & $10.481^{*}$ & 28.472 & 11.296 & 7.399 & 2.424 & 43.571 & 22.764 & 14.704 \\
\hline Türkiye & 0.386 & 27.210 & 10.548 & 6.653 & 1.371 & 42.442 & 22.504 & 14.678 \\
\hline
\end{tabular}

Not: *, ** ve *** “Ho= BBSO, BÖSK'ün nedeni değildir” ve “BÖSK, BBSO'nun nedeni değildir" boş hipotezlerinin sırasıyla \%90, \%95 ve \%99 önem düzeyinde reddedildiğini ifade etmektedir. Kritik değerler 1.000 bootstrap tekrarından elde edilmiştir.

Bu kapsamda ilk olarak Brüt Sermaye Oluşumu Büyüme Oranı (BBSO)'nun Özel Sektöre Kullandırılan Kredilerdeki Büyüme Oranı (BÖSK) üzerindeki etkisi analiz edilmiştir. Brezilya, Çin, Endonezya, Hindistan, Meksika, Rusya ve Türkiye arasından Endonezya ve Rusya'da Brüt Sermaye Oluşumu Büyüme Oranının, Özel Sektöre Kullandırılan Kredilerdeki Büyüme Oranının nedeni olduğu görülmektedir. Özel Sektöre Kullandırılan Kredilerdeki Büyüme Oranının (BÖSK), Brüt Sermaye Oluşumu Büyüme Oranı (BBSO) üzerindeki etkisi incelendiğinde analiz edilen ülkeler için herhangi bir nedensellik ilişkisi bulunamamıştır. Tablo 4 'te diğer bir ekonomik büyüme göstergesi olan Gayri Safi Yurt İçi Hâsıla Büyüme Oranı (BGSYH) ve Özel Sektöre Kullandırılan Kredilerdeki Büyüme Oranı (BÖSK) arasındaki nedensellik ilişkisi incelenmiştir.

Tablo 4. Panel Nedensellik Analizi Sonuçları (Model II)

\begin{tabular}{|l|l|l|l|l|l|l|l|l|}
\hline \multicolumn{5}{|l|}{ BGSYH $\rightarrow$ BÖSK } & \multicolumn{3}{l}{ BÖSK $\rightarrow$ BGSYH } \\
\hline Ülkeler & İstatistik & \multicolumn{2}{l}{ Bootstrap Kritik Değerler } & İstatistik & \multicolumn{2}{l}{$\begin{array}{l}\text { Bootstrap } \\
\text { Değerler }\end{array}$} & Kritik \\
\hline & & $1 \%$ & $5 \%$ & $10 \%$ & & $1 \%$ & $5 \%$ & $10 \%$ \\
\hline Brezilya & 0.658 & 25.941 & 13.922 & 8.770 & 2.365 & 30.121 & 13.146 & 8.681 \\
\hline Çin & 0.256 & 28.578 & 12.627 & 8.500 & $14.397^{* *}$ & 32.533 & 14.334 & 10.139 \\
\hline Endonezya & 0.294 & 26.442 & 12.974 & 7.927 & 3.102 & 41.256 & 18.940 & 13.188 \\
\hline Hindistan & 4.054 & 27.515 & 13.567 & 8.526 & 0.000 & 30.429 & 14.488 & 9.151 \\
\hline Meksika & 1.605 & 27.392 & 10.675 & 7.181 & 0.261 & 32.904 & 17.556 & 10.968 \\
\hline Rusya & 2.004 & 19.235 & 10.141 & 7.302 & 1.161 & 35.491 & 17.937 & 12.195 \\
\hline Türkiye & 0.937 & 31.511 & 15.448 & 10.107 & $19.076^{* *}$ & 32.439 & 16.854 & 10.649 \\
\hline
\end{tabular}

Not: ", ** ve *** “Ho= BGSYH, BÖSK'ün nedeni değildir" ve “BÖSK, BGSYH'nin nedeni değildir" boş hipotezlerinin sırasıyla \%90, \%95 ve \%99 önem düzeyinde reddedildiğini ifade etmektedir. Kritik değerler 1.000 bootstrap tekrarından elde edilmiştir.

Analizler sonucunda Gayri Safi Yurt İçi Hâsıla Büyüme Oranının (BGSYH) Özel Sektöre Kullandırılan Kredilerdeki Büyüme Oranının (BÖSK) nedeni olduğu yönünde herhangi bir 
bulguya ulaşılamamıştır. Buna göre E7 ülkelerinin hiç birinde Gayri Safi Yurt İçi Hâsıla Büyüme Oranının Özel Sektöre Kullandırılan Kredilerdeki Büyüme Oranının (BÖSK) nedeni olmadı̆̆1 görülmektedir. Ancak E7 ülkeleri arasında Çin ve Türkiye'de Özel Sektöre Kullandırılan Kredilerdeki Büyüme Oranından (BÖSK), Gayri Safi Yurt İçi Hâsıla Büyüme Oranına (BGSYH) doğru bir nedensellik ilişkisinin varlığ III kapsamında Brüt Sermaye Oluşumu Büyüme Oranı (BBSO) ve Geniş Kapsamlı Para Arzı/Dar Kapsamlı Para Arzı (M2/M1) arasındaki ilişkinin incelenmesi sonucunda elde edilen bulgulara yer verilmiştir.

Tablo 5. Panel Nedensellik Analizi Sonuçları (Model III)

\begin{tabular}{|l|l|l|l|l|l|l|l|l|}
\hline & \multicolumn{7}{|l}{ BBSO $\rightarrow$ M2/M1 } & \multicolumn{2}{l}{ M2/M1 $\rightarrow$ BBSO } \\
\hline Ülkeler & İstatistik & \multicolumn{2}{l}{ Bootstrap Kritik Değerler } & İstatistik & \multicolumn{2}{l|}{ Bootstrap } \\
Değerler & Kritik \\
\hline & & $1 \%$ & $5 \%$ & $10 \%$ & & $1 \%$ & $5 \%$ & $10 \%$ \\
\hline Brezilya & 0.975 & 62.000 & 33.889 & 27.283 & 0.235 & 15.215 & 6.873 & 4.741 \\
\hline Çin & 7.691 & 86.165 & 52.584 & 33.200 & 0.057 & 14.712 & 7.560 & 3.880 \\
\hline Endonezya & 5.345 & 101.814 & 40.248 & 22.450 & 0.002 & 41.280 & 14.715 & 7.942 \\
\hline Hindistan & 5.682 & 56.207 & 34.133 & 24.154 & 0.305 & 16.062 & 7.375 & 4.581 \\
\hline Meksika & 6.626 & 42.035 & 23.248 & 15.711 & 3.281 & 18.444 & 11.144 & 7.466 \\
\hline Rusya & 0.414 & 62.351 & 30.405 & 19.694 & 6.067 & 30.339 & 14.157 & 9.425 \\
\hline Türkiye & 0.069 & 93.553 & 24.638 & 11.986 & 1.796 & 45.894 & 21.753 & 14.883 \\
\hline
\end{tabular}

Not: ", ** ve *** "H0= BBSO, M2/M1'in nedeni değildir" ve "M2/M1, BBSO'nun nedeni değildir" boş hipotezlerinin sırasıyla \%90, \%95 ve \%99 önem düzeyinde reddedildiğini ifade etmektedir. Kritik değerler 1.000 bootstrap tekrarından elde edilmiştir.

Model III kapsamındaki nedensellik ilişkisinin analiz edilmesi sonucunda E7 ülkelerinden hiç birisi için Brüt Sermaye Oluşumu Büyüme Oranından (BBSO) Geniş Kapsamlı Para Arzı/Dar Kapsamlı Para Arzı (M2/M1)'na doğru bir nedensellik ilişkisi bulunamamıştır. Benzer şekilde Brezilya, Çin, Endonezya, Hindistan, Meksika, Rusya ve Türkiye'de Geniş Kapsamlı Para Arzı/Dar Kapsamlı Para Arzının (M2/M1) Brüt Sermaye Oluşumu Büyüme Oranının (BBSO) nedeni olmadığ görülmektedir. Son olarak Tablo 6'da Gayri Safi Yurt İçi Hâsıla Büyüme Oranı (BGSYH) ve Geniş Kapsamlı Para Arzı/Dar Kapsamlı Para Arzı (M2/M1) arandaki nedensellik ilişkisinin incelenmesi sonucunda ulaşılan bulgular sunulmuştur. 
Tablo 6. Panel Nedensellik Analizi Sonuçları (Model IV)

\begin{tabular}{|l|l|l|l|l|l|l|l|l|}
\hline & \multicolumn{2}{|l}{ BGSYH $\rightarrow$ M2/M1 } & \multicolumn{2}{l}{ M2/M1 $\rightarrow$ BGSYH } \\
\hline Ülkeler & İstatistik & \multicolumn{2}{|l}{ Bootstrap Kritik Değerler } & İstatistik & \multicolumn{2}{l}{ Bootstrap } \\
Değerler & Kritik \\
\hline & & $1 \%$ & $5 \%$ & $10 \%$ & & $1 \%$ & $5 \%$ & $10 \%$ \\
\hline Brezilya & 0.248 & 78.317 & 46.954 & 31.479 & 0.325 & 21.201 & 11.202 & 7.878 \\
\hline Çin & 15.053 & 60.990 & 39.612 & 29.317 & 1.276 & 16.818 & 8.785 & 5.682 \\
\hline Endonezya & 7.479 & 70.397 & 39.264 & 27.913 & 0.486 & 16.077 & 8.314 & 5.678 \\
\hline Hindistan & 0.439 & 90.928 & 49.002 & 30.364 & 1.328 & 17.554 & 9.252 & 6.085 \\
\hline Meksika & $21.149^{*}$ & 40.656 & 24.223 & 16.281 & 2.743 & 16.442 & 9.108 & 5.690 \\
\hline Rusya & 0.000 & 47.897 & 25.862 & 19.555 & 3.038 & 27.762 & 15.435 & 9.970 \\
\hline Türkiye & 0.132 & 61.901 & 35.053 & 23.893 & 1.576 & 30.740 & 13.537 & 8.126 \\
\hline
\end{tabular}

Not: ", ** ve *** "H0= BGSYH, M2/M1'in nedeni değildir" ve "M2/M1, BGSYH'ın nedeni değildir" boş hipotezlerinin sırasıyla \%90, \%95 ve \%99 önem düzeyinde reddedildiğini ifade etmektedir. Kritik değerler 1.000 bootstrap tekrarından elde edilmiştir.

Tablo 6 incelendiğinde E7 ülkeleri arasından Meksika'da Gayri Safi Yurt İçi Hâsıla Büyüme Oranının (BGSYH) Geniş Kapsamlı Para Arzı/Dar Kapsamlı Para Arzının (M2/M1) nedeni olduğu görülmektedir. Ancak, incelenen E7 ülkeleri arasında hiçbir ülkede Geniş Kapsamlı Para Arzı/Dar Kapsamlı Para Arzının (M2/M1), Gayri Safi Yurt İçi Hâsıla Büyüme Oranının (BGSYH) nedeni olmadığı görülmektedir.

Genel olarak değerlendirildiğinde, Çin ve Türkiye'de finansal yenilik göstergelerinin ekonomik büyümenin nedeni olduğu, Endonezya, Meksika ve Rusya'da büyüme oranlarının finansal yenilik göstergelerinin nedeni olduğu, Brezilya ve Hindistan'da ise finansal yenilik ve ekonomik büyüme göstergeleri arasındaki herhangi bir nedensellik ilişkisinin varlığına bir bulguya ulaşılamadığı görülmektedir.

\section{SONUÇ VE ÖNERILER}

Son 40 yılda finansal serbestleşme hareketleri ile başlayan sermaye hareketleri fonların taraflar arasında transferi görevini yerine getiren finansal piyasaların etkinliğinin artırılması yönündeki çabalara hız kazandırmıştır. Sermayenin taraflar arasında etkin dağılımını sağlayan yeni finansal araçlar, yeni finansal kurumlar ya da yeni finansal süreçlerin geliştirilmesi olarak tanımlanabilen finansal yenilikler ise bu süreçte önem kazanmıştır. Finansal yenilikler finansal piyasaların etkinliğini ve verimliliğini artırarak finansal sistemin gelişimine katkı sunabilmektedir. Finansal sistemin gelişimi diğer bir değişle finansal gelişme kavramı ile ilişkili olan birçok makroekonomik faktörden bahsetmek mümkün 
olmakla birlikte bu faktörlerin başında ekonomik büyüme geldiğini söylemek yanlış olmayacaktır. Söz konusu ilişkinin çok sayıda geçmiş çalışmaya araştırma konusu olduğu görülmektedir. Ancak, finansal yenilik ve ekonomik büyüme arasındaki ilişkilerin incelendiği araştırmaların oldukça sınırlı kaldığ 2)'ın belirttiği gibi finansal yenilik kavramının tanımlanması ve finansal yenilikleri ortaya çıkaran unsurlar hakkında fikir birliğinin olmayışının yanı sıra finansal yeniliklerin temsilcisi olan finansal göstergelerin belirlenmesindeki ve veriye ulaşılmasındaki zorlukların da söz konusu çalışmaların kısıtlı kalmasının temel nedenleri arasında yer aldığı düşünülmektedir. Geçmiş çalışmalar içinde söz konusu ilişkiyi E7 ülkeleri için inceleyen bir çalışmaya da rastlanılmamıştır.

G20 ülkeleri arasında sıralanan ve yakın gelecekte G7 ülkelerinin yerini alabileceği tahmin edilen E7 ülkelerinde ekonomik büyümeye ilişkin dinamiklerinin belirlenmesi ekonomik büyümenin hızlandırılması ve ülkelerin ekonomik rekabet gücünün artırılması açısından önem taşımaktadır. Geçmiş çalışmalarda birçok makroekonomik faktörün ekonomik büyüme üzerindeki etkisinin incelenmesine rağmen finansal yeniliklerin ekonomik büyüme üzerindeki etkisinin detaylı olarak incelenmediği ve üzerinde analiz yürütülen ülkelerin sınırlı kaldığı dikkat çekmektedir. Finansal yenilikler diğer makroekonomik faktörlerden farklı olarak bir yenilik olarak ortaya çıktığından etkinlerinin zaman içindeki gelişim süreci farklılaşabilmektedir. Bunun yanı sıra, finansal yeniliklerin makroekonomik faktörlerden farklı olarak dışsal faktörlerden daha az etkilenebildiği düşünüldüğünde ekonomik büyüme üzerindeki etkisinin daha görülür ve kalıcı olabilmektedir. Bu noktadan hareketle, finansal yeniliklerin ekonomik büyüme üzerinde etkili olduğu ülkelerde finansal yenilikleri teşvik edici politikalar ile ekonomik büyümenin artırılabilmesi dolayısıyla da uluslararası arenada rekabet gücünün artırılması olası görülmektedir. Bu nedenle, finansal yenilikler ve ekonomik büyüme arasındaki ilişkilerin belirlenmesinin politika geliştiriciler tarafından önemli olduğu düşünülmektedir. Bu çalışma kapsamında, Brezilya, Çin, Endonezya, Hindistan, Meksika, Rusya ve Türkiye'den oluşan E7 ülkelerinde 2002-2019 dönemi için yıllık veriler kullanılarak finansal yenilik ve ekonomik büyüme arasındaki ilişki incelenerek literatüre katkı sunulması amaçlanmıştır.

Çalışma kapsamında elde edilen bulgular E7 ülkeleri arasında Çin ve Türkiye'de finansal yeniliklerin ekonomik büyümenin nedeni olduğunu göstermiştir. Buna göre, Çin ve Türkiye'de finansal yeniliklerin teşvik edilmesi ve finansal yeniliklerin nicelik ve nitelik olarak geliştirilmesi yolu ile ekonomik büyümenin artırılması mümkün gözükmektedir. Buna göre, söz konusu ülkelerde finansal yenilikler ekonomik büyümenin tahmin gücünün artırılmasına da katkı sunmaktadır. Bunun yanı sıra elde edilen bulgular, Endonezya, Meksika ve Rusya'da büyüme oranlarının finansal yeniliklerin nedeni olduğunu göstermiştir. Buna göre, söz konusu ülkelerde ekonomik büyümenin finansal yenilikleri ortaya çıarmada teşvik edici bir unsur olduğu söylenebilir. Bir başka ifade ile söz konusu ülkelerde ekonomik büyüme, finansal sistemin etkinliğini artırarak finansal yenilikleri ortaya çıاkmasına neden olabilmektedir. İncelenen diğer ülkeler olan Brezilya ve Hindistan'da ise finansal yenilikler ve ekonomik büyüme arasında herhangi bir nedensellik ilişkisi bulunamamıştır. Bu sonuçlara göre, Brezilya ve Hindistan'da finansal yeniliklerin ekonomik büyümenin sağlanmasında bir politika aracı olarak kullanılmasının etkin bir politika olmadığı görülmektedir. 
$\mathrm{Bu}$ çalışmadan sonra konu üzerinde yürütülecek olan araştırmalarda farklı ülke örnekleri üzerine yürütülen analizlerin, karşılaştırılabilir sonuçların elde edilebilmesi noktasında önemli olduğu düşünülmektedir.

\section{KAYNAKÇA}

Abdouli, M. \& Hammami, S. (2020). Economic growth, environment, FDI inflows, and financial development in middle east countries: fresh evidence from simultaneous equation models. Journal of Knowlege Economics, 11, 479-511.

Acaravc1, S., Öztürk, İ. \& Acaravc1, A. (2009). Financial development and economic growth: literature survey and empirical evidence from Sub-Saharan African countries, South African Journal of Economic and Management Sciences, 12(1), 11-27.

Ajide, F. (2016). Financial innovation and sustainable development in selected countries in West Africa. Journal of Entrepreneurship, Management and Innovation, Fundacja Upowszechniająca Wiedzę i Naukę "Cognitione", 2(3), 85-111.

Allen, D. S. \& Ndikumana, L. (1998). Financial intermediation and economic growth in Southern Africa. Journal of African Economies, 9(2), 132-160.

Amore, M.D., Schneider, C., \& Žaldokas, A. (2013). Credit supply and corporate innovation. Journal of Financial Economics, 109, 835-855.

Ansong, A. Marfo-Yiadom, E. \& Ekow-Asmah, E. (2011). The effects of financial innovation on financial savings: evidence from an economy in transition. Journal of African Business, 12(1), 93-113.

Arestis, P. \& Demetriades, P. (1997). Financial development and economic growth: Assessing the evidence. The Economic Journal, 107(442), 783-799.

Arrau, P. De Gregorio, J. Reinhart, C.M. \& Wickham, P. (1995). The demand for money in developing countries: Assessing the role of financial innovation. Journal of Development Economics, 46(2), 317-340.

Aslan, A. G. Ö. ve Küçükaksoy, İ. (2006). Finansal gelişme ve ekonomik büyüme ilişkisi: Türkiye ekonomisi üzerine ekonometrik bir uygulama. Ekonometri ve İstatistik EDergisi, (4), 25-38.

Asteriou, D. \& Spanos, K. (2019). The relationship between financial development and economic growth during the recent crisis: Evidence from the EU. Finance Research Letters, 28, 238-245.

Bhatt, V.V. (1987). Financial Innovations and Credit Market Evolution. Economic and Political Weekly, 22(22), 45-54.

Baltagi, B. H. Feng, Q. \& Kao, C. (2012). A Lagrange Multiplier test for cross-sectional dependence in a fixed effects panel data model. Journal of Econometrics, 170(1), 164177.

Bank for International Settlement-BIS. (1986). Recent innovations in international banking (Cross Report). Araştırma Raporu. URL: https://www.bis.org/publ/ecsc01.htm, (Erişim: 04.08.2020) 
Banxico. (2020). Economic information system (SIE). URL: https://www.banxico.org.mx/SieInternet/consultarDirectorioInternetAction.do?sector $=3$ veaccion $=$ consultarCuadroAnaliticoveidCuadro=CA452velocale $=$ en $\quad$ (Erişim: 01.12.2020)

Bara, A. \& Mudxingiri, C. (2016) Financial innovation and economic growth: evidence from Zimbabwe. Investment Management and Financial Innovations, 13(2), 65-75.

Bara A., Mugano, G. \& Le Roux, P. (2016) Financial innovation and economic growth in the SADC. African Journal of Science, Technology, Innovation and Development, 8(5), 483-495.

Beck, T. Chen, T., Lin, C., \& Song, F.M. (2016). Financial innovation: The bright and the dark sides, Journal of Banking ve Finance, 72, 28-51.

Bernier, M., \& Plouffe, M. (2019). Financial innovation, economic growth, and the consequences of macroprudential policies. Research in Economics, 73, 162-173.

Bertay, A.C. Gong, D. \& Wagner, W. (2017). Securitization and economic activity: The credit composition channel. Journal of Financial Stability, 28, 225-239.

Breusch, T.S. \& Pagan, A.R. (1980). The Lagrange multiplier test and its applications to model specification in econometrics. The Review of Economic Studies, 47(1), 239-253.

Büyükakın, F. Cengiz, V. ve Pehlivanoğlu, F. (2011). Türkiye'de finansal yenilik-tüketim harcamaları ilişkisi (Ampirik Analiz: 1998-2008). Atatürk Üniversitesi İktisadi ve İdari Bilimler Dergisi, 10. Ekonometri ve İstatistik Sempozyumu Özel Sayısı, 207-222.

Calderón, V. \& Liu, L. (2003). The direction of causality between financial development and economic growth. Journal of Development Economics, 72(1), 321-334.

Chou, Y. K. (2007). Modeling financial innovation and economic growth: Why the financial sector matters to the real economy. The Journal of Economic Education, 38(1), 78-90.

Cömert, H. \& Epstein, G. (2016). Finansal yenilik yazınındaki son gelişmeler (No. 1604). STPS-Science and Technology Policy Studies Center, Middle East Technical University. URL: https://stps.metu.edu.tr/en/system/files/stps_wp_1604.pdf, (Erişim: 08.04.2021)

Demetriades, P.O. \& Hussein, K.A. (1996). Does financial development cause economic growth? Time-series evidence from 16 countries. Journal of Development Economics, 51(2), 387-411.

Durusu-Ciftci, D. Ispir, M.S. \& Yetkiner, H. (2017). Financial development and economic growth: Some theory and more evidence. Journal of Policy Modeling, 39(2), 290-306.

FRED-Federal Reserve Bank of St. Louis. (2020). Federal Reserve Economic Data. URL: https://fred.stlouisfed.org/, (Erişim: 08.04.2020).

Fetai, B. T. (2018). Does financial development accelerate economic growth? An empirical analysis of European countries in transition. Journal of Financial Economic Policy, 10(3), 426-435. 
Frame, W. S. \& White, L.J. (2014) Technological Change, Financial Innovation, and Diffusion in Banking NYU Working Paper No. 2451/33549. URL: https://ssrn.com/abstract=2380060, (Erişim: 08.04.2020).

Gregorio, J. \& Guidotti, P.E. (1995). Financial development and economic growth. World Development, 2(3), 433-448.

Günceler, B. \& Kesebir, M. (2018). Menkul Kıymetleştirme Banka Kredilerine Kıyasla Firmalar için Alternatif Fonlama Kaynağı Olabilir mi? Türkiye'de Hizmet Sağlayan Şirketlere Uygulanabilirliği Bakımından İncelenmesi. International Journal of Entrepreneurship and Management Inquiries, 2(3), 75-90.

Gündoğdu, A. \& Taşkın, F.D. (2017). Analysis of the relationship between financial innovation and the performance of Turkish banking system. International Review of Economics and Management, 5(3), 16-32.

Hao, J. \& Hunter, W.C. (1997). A Test of the impact of financial innovation on economic growth. Managerial Finance, 23(11), 64-78.

Hassan, M.K., Sanchez, B. \& Yu, J.S. (2011). Financial development and economic growth: New evidence from panel data. The Quarterly Review of Economics and Finance, 51(1), 88-104.

Hermes, N. \& Lensink, R. (2003). Foreign direct investment, financial development and economic growth. The Journal of Development Studies, 40(1), 142-163.

Jenkinson, N. Penalver, A. \& Vause, N. (2008). Financial innovation: what have we learnt?.Bank of England Quarterly Bulletin, Çalışma Metni. URL: https://www.bankofengland.co.uk/speech/2008/financial-innovation-what-have-welearnt ${ }_{\llcorner}$Erişim: 08.04.2020).

Jung, W.S. (1986). Financial development and economic growth: international evidence. Economic Development and Cultural Change, 34(2), 333-346.

Idun, A.A. \& Aboagye, Q.Q. (2014), Bank competition, financial innovations and economic growth in Ghana. African Journal of Economic and Management Studies, 5(1), 30-51.

Kandır, S.Y. İskenderoğlu, Ö. \& Önal, Y.B. (2007). Finansal gelişme ve ekonomik büyüme arasındaki ilişkinin araştırılması. Çukurova Üniversitesi Sosyal Bilimler Enstitüsü Dergisi, 16(2), 311-326.

Kaplan, C. (1999). Finansal yenilikler ve piyasalar üzerine etkileri: Türkiye örneği. TCMB Araştırma Genel Müdürlüğü Tartışma Tebliği No: 9910. URL: https://core.ac.uk/download/pdf/7061383.pdf, (Erişim: 12.07.2020).

Khan, M.S. \& Senhadji, A.S. (2000). Financial development and economic growth. International Monetary Fund, Çalışma Metni, 209. URL: https://www.elibrary.imf.org/view/journals/001/2000/209/article-A001-en.xml, (Erişim: 08.04.2020).

Khan, A.B., Fareed, M., Salameh, A.A. \& Hussain, H. (2021). Financial innovation, sustainable economic growth, and credit risk: A case of the ASEAN banking sector. Frontiers in Environmental Science, 9, 729922. doi: 10.3389/fenvs.2021.729922. 
Kónya, L. (2006). Exports and growth: Granger causality analysis on OECD countries with a Panel Data Approach. Economic Modeling, 23(6), 978-992.

Laeven, L. Levine, R. \& Michalopoulos, S. (2015). Financial innovation and endogenous growth. Journal of Financial Intermediation, 24(1), 1-24.

Laumas, P. (1962). Schumpeter's Theory of Economic Development and Underdeveloped Countries. The Quarterly Journal of Economics, 76(4), 653-659.

Levine, R. (2005). Finance and growth: Theory and evidence, in Press Aghion and S. Durlauf, eds: Handbook of Economic Growth (North-Holland Elsevier Publishers, Amsterdam).URL:http://faculty.haas.berkeley.edu/ross_levine/papers/forth_book_du rlauf_finngrowth.pdf, (Erişim: 08.04.2020).

Merton, R. C. (1992). Financial innovation and economic performance. Journal of Applied Corporate Finance, 4( 4), 12-22.

Merton, R.C. (1995). Financial innovation and the management and regulation of financial institutions. Journal of Banking ve Finance,19, 461-481.

Miller, M. H. (1986). Financial innovation: The last twenty years and the next. Journal of Financial and Quantitative Analysis, 459-471.

Mishra, P.K. (2009). Financial innovation and economic growth - A theoretical approach. The Research Network. 4. 59-64. 10.2139/ssrn.1262658.

Nazir, M.R., Tan, Y. \& Nazir, M. I. (2020). Financial innovation and economic growth: Empiricalevidence from China, India and Pakistan. International Journal of Finance \& Economics, 26, 6036-6059.

Okafor, I. G. Chijindu, E. H. \& Chikezie, A.K. (2017). Does financial innovation drive growth? Empirical analysis of the Nigerian case. British Journal of Economics, Management ve Trade, 16(3), 1-10.

Öncü, M. A. Mesci, M. ve Şahin, Ö. (2012). Finansal yeniliklerin işletme performansına etkisi: İstanbul'daki turizm işletmelerine yönelik bir araştırma. Atatürk Üniversitesi İktisadi ve İdari Bilimler Dergisi, 26(3-4), 125-141.

Öncü, M. A. Mesci, M. Şahin, Ö. ve Faikoğlu, S. (2013). Finansal yeniliklerin işletme performansına etkisi: İstanbul'daki hizmet işletmelerine yönelik bir araştırma. Alanya İşletme Fakültesi Dergisi, 5(3), 119-129.

Öztürk, İ. (2008). Financial development and economic growth: empirical evidence from Turkey, Applied Econometrics and International Development, 8(1), 85-98.

Öztürk, İ. \& Acaravc1, A. (2013). The long-run and causal analysis of energy, growth, openness and financial development on carbon emissions in Turkey. Energy Economics, 36, 262-267.

Pesaran, M.H. (2004). General diagnostic tests for cross section dependence in panels. Cambridge Working Papers in Economics No: 0435, Faculty of Economics, University of Cambridge. 
Pradhan, R. P. Arvin, M. B. Hall, J. H. \& Nair, M. (2016). Innovation, financial development and economic growth in Eurozone countries. Applied Economics Letters, 23(16), 1141-1144.

Qamruzzaman, M. \& Wei, J. (2018). Financial innovation, stock market development, and economic growth: An application of ARDL Model, International Journal of Financial Studies, 6(3), 1-30.

Ram, R. (1999). Financial development and economic growth: Additional evidence, The Journal of Development Studies, 35(4), 164-174.

Sbia, R., Shahbaz, M. \& Öztürk, İ. (2017). Economic growth, financial development, urbanisation and electricity consumption nexus in UAE. Economic Research, 30(1), 527-549.

Schumpeter J. (1934). Theory of economic development: An inquiry into profits, capital, credit, interest, and the business cycle. Harvard University Press, Cambridge, MA.

Silber, W. L. (1983). The process of financial innovation. The American Economic Review, 73(2), 89-95.

Shiller, R. J. (2004). Radical financial innovation. Cowles Foundation Discussion Paper No. 1461. Çalışma Metni. URL: https://ssrn.com/abstract=537402, (Erişim: 08.04.2020).

Shiller, R. J. (2013) Capitalism and financial innovation. Financial Analysts Journal, 69(1), 2125.

Škare, M. Sinković, D. \& Porada-Rochoń, M. (2019). Financial development and economic growth in Poland 1990-2018. Technological and Economic Development of Economy, 25(2), 103-133.

Soltani, H. Triki, M. B. Ghandri, M. \& Abderzag, F. T. (2021). Does geopolitical risk and financial development matter for economic growth in MENA countries?. Journal of International Studies, 14(1), 103-116.

Sweet, S. A. \& Grace-Martin, K. (2012). Data analysis with SPSS: A first course in applied statistics (4th edition). Pearson. URL: https://www.pearsonhighered.com/assets/samplechapter/0/2/0/5/0205019676.pdf, (Erişim: 18.11.2021).

Tahir, S.H., Shah, S., Arif, F., Ahmad, G., Aziz, Q. \& Ullah, M. R. (2018). Does financial innovation improve performance? An analysis of process innovation used in Pakistan. Journal of Innovation Economics \& Management 27(3), 195-214.

Thanawala, K. (1994). Schumpeter's theory of economic development and development economics. Review of Social Economy, 52(4), 353-363.

Tufano, P. (2002). Financial innovation. The Handbook of the Economics of Finance (North Holland), George Constantinides (Ed.). URL: http://www.dklevine.com/archive/fininnov_tufano_june2002.pdf_(Erişim: 08.04.2020).

Valverde, C.S. Del Paso, R.L. \& Fernández, F. R. (2007). Financial innovations in Banking: Impact on regional growth. Regional Studies, 41(3), 311-326. 
World Development Indicators (2020). Databank. URL: https://databank.worldbank.org/source/world-development-indicators, (Erişim: 08.04.2020).

Wu, C.F. Huang, S.C. Chang, T. Chiou, C.C. Hsueh, H.P. (2020). The nexus of financial development and economic growth across major Asian economies: Evidence from bootstrap ARDL testing and machine learning approach, Journal of Computational and Applied Mathematics, 372,1-14.

Yetiz, F. ve Ünal, A. E. (2018). Finansal yeniliklerin gelişimi ve Türk bankacılık sektörüne etkileri. Kastamonu University Journal of Economics ve Administrative Sciences, 20(4), 117-135.

Zhang, J. Wang, L. \& Wang, S. (2012). Financial development and economic growth: Recent evidence from China. Journal of Comparative Economics, 40(3), 393-412. 